\title{
miR-195 inhibits cell proliferation and angiogenesis in human prostate cancer by downregulating PRR11 expression
}

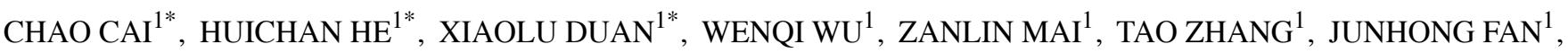 \\ TUO DENG ${ }^{1}$, WEN ZHONG ${ }^{1}$, YONGDA LIU ${ }^{1}$, WEIDE ZHONG ${ }^{1,2}$ and GUOHUA ZENG ${ }^{1}$ \\ ${ }^{1}$ Department of Urology, Minimally Invasive Surgery Center, The First Affiliated Hospital of Guangzhou Medical University \\ and Guangdong Key Laboratory of Urology, Guangzhou, Guangdong 510230; \\ ${ }^{2}$ Department of Urology, Guangdong Key Laboratory of Clinical Molecular Medicine and Diagnostics, \\ Guangzhou First People's Hospital, Guangzhou Medical University, Guangzhou, Guangdong 510180, P.R. China
}

Received July 17, 2017; Accepted January 24, 2018

DOI: $10.3892 /$ or.2018.6240

\begin{abstract}
R-195-5p (miR-195) has been proven to be a critical regulator in the progression of prostate cancer $(\mathrm{PCa})$. To identify additional targets and molecular functions of miR-195, we overexpressed miR-195 by transient oligonucleotide transfection in DU145 and LNCaP cells and examined the effects. RNA-based microarray and dual-luciferase assays were carried out to identify novel targets of miR-195, while in vitro functional assays, a subcutaneous xenograft model, tissue microarray (TMA) analysis and a cohort of publicly available data (Taylor cohort) were used to investigate the biological function and clinical value of miR-195 targeting. The results shown that miR-195 overexpression could markedly suppress cellular proliferation and tube formation compared with miR-negative control. The RNA-based microarray identified a total of 153 differentially regulated genes with fold changes of $\leq 1.51$, including 138 (90.2\%) downregulated and $15(9.8 \%)$ upregulated genes. Among the downregulated genes, we found that proline-rich protein 11 (PRR11) combined with miR-195 expression (miR-195/PRR11) could be used as an independent predictor of the risk of biochemical recurrence in the Taylor
\end{abstract}

Correspondence to: Professor Guohua Zeng, Department of Urology, Minimally Invasive Surgery Center, The First Affiliated Hospital of Guangzhou Medical University and Guangdong Key Laboratory of Urology, 1 Kangda Road, Haizhu, Guangzhou, Guangdong 510230, P.R. China

E-mail: gzgyzgh@vip.sina.com

Professor Weide Zhong, Department of Urology, Guangdong Key Laboratory of Clinical Molecular Medicine and Diagnostics, Guangzhou First People's Hospital, Guangzhou Medical University, 1 Panfu Road, Yuexiu, Guangzhou, Guangdong 510180, P.R. China E-mail: zhongwd2009@live.cn

${ }^{*}$ Contributed equally

Key words: hsa-miR-195, prostate cancer, proline-rich protein 11, prognosis, progression cohort. Additionally, the dual-luciferase assay identified PRR11 as a novel target of miR-195, and the in vitro assays indicated that PRR11 abrogated the suppressive effects of miR-195 on cell proliferation, tube formation and cell cycling. Furthermore, the subcutaneous tumor xenograft model indicated that knockdown of PRR11 inhibited xenograft growth and angiogenesis, while the results of the TMA and Taylor cohort analyses collectively demonstrated that PRR11 expression was upregulated in aggressive tumors and is associated with poor clinical outcome. Taken together, these findings further illustrate the suppressive role of miR-195 in PCa, and indicate a novel role of PRR11 in PCa. Importantly, the newly identified miR-195/PRR11 axis may aid with identifying potential therapeutic targets in $\mathrm{PCa}$.

\section{Introduction}

Prostate cancer (PCa) is a disease with genomic, pathological and clinical heterogeneity (1). Routine prostate-specific antigen (PSA) screening for PCa aids in the detection of localized early stage tumors in most cases (2); however, it can also lead to unnecessary diagnoses or overtreatment of indolent $\mathrm{PCa}$ (3). In addition, traditional clinicopathological parameters fail to precisely distinguish cases, again leading to inappropriate treatment (4). Thus, molecular biomarkers for PCa diagnosis, prognosis and treatment response have been investigated over previous decades, in order to offer more personalized medicine.

MicroRNAs (miRNAs/miRs) are evolutionarily conserved, short ( 18-22 nucleotides), non-coding, singlestranded RNA molecules that act as posttranscriptional gene regulators by targeting the 3'untranslated region (3' UTR) of target mRNAs (5). Many studies have shown that miRNAs serve a critical role in various tumors (6-8). In particular, studies have investigated the potential use of miRNAs as biomarkers in the diagnosis, prognosis and treatment of cancers (7) including PCa (8). In PCa, a number of miRNAs, such as miR-205, miR-221, miR-222 and miR-145, have been demonstrated to be consistently dysregulated (9-12). miRNAs or miRNA signatures have potential clinical use in almost all aspects of PCa management (13). Notably, miR-195, located 
on chromosome $17 \mathrm{p} 13.1$ (positioned from $6,881,953$ to $6,862,065 \mathrm{bp}$ ) and belonging to the miR-15 family (14), has been demonstrated to be a critical regulator in the development and progression of tumors (15-20). In our previous study, we identified hsa-miR-195-5p (miR-195) as a novel prognostic indicator for $\mathrm{PCa}$. We also found that miR-195 exerted its molecular effects by targeting RPS6KB1 (21). Therefore, in this study, we aimed to continue our investigations into the molecular function of miR-195 and to identify its targets in PCa.

\section{Materials and methods}

Patients and tissue samples. The tissue microarrays (TMAs), including 126 primary PCa tissues and 22 adjacent noncancerous prostate tissues along with detailed clinical information of the samples, were purchased from Xi'an Alenabio Biotech Co.,Ltd. (cat no.: PR752 \& PR753). All human tissues were collected under Institutional Review Board (IRB) and Health Insurance Portability and Accountability (HIPPA) approved protocols. Patients known to have undergone chemotherapy and/or radiotherapy prior to tissue isolation were excluded from the study.

Additionally, a cohort from the Memorial Sloan-Kettering Cancer Center (the Taylor cohort) with publicly available data (GEO accession no. GSE21032), including 150 primary PCa tissues and 29 adjacent non-cancerous prostate tissues, was assessed in regards to clinicopathological parameters. Of these cases, 111 of the primary PCa tissues and all of the non-cancerous tissues had available miRNA microarray expression data (22). Biochemical recurrence (BCR) was defined as PSA $\geq 0.2 \mathrm{ng} / \mathrm{ml}$ on two consecutive measurements after radical prostatectomy. BCR-free survival was defined as the time interval between initial surgery and the date of BCR. Overall survival was determined as the time interval between the initial surgery and the date of the last follow-up or patient death.

Animals. Animal housing and the experiments in this study were performed in compliance with the guidelines of the Institute for Laboratory Animal Research at Guangzhou Medical University (Guangzhou, China). A total of 32 BALB/c nude mice (4- to 5-week-old males) were purchased from Guangdong Medical Laboratory Animal Center and were housed in wire-top cages ( 5 mice per cage) with sawdust bedding in an isolated, clean, air-conditioned room at a temperature of $25-26^{\circ} \mathrm{C}$ and relative humidity of $\sim 50 \%$ under a 12-h light/dark cycle.

Cell culture. The human PCa cell lines, LNCaP (cat. no. 63462566) and DU145 (cat. no. 61761869) were purchased from the American Type Culture Collection (ATCC; Manassas, VA, USA) in 2015 and were cultured in RPMI-1640 medium (Hyclone, USA) supplemented with $10 \%$ fetal bovine serum (Gibco, USA), 2 mM L-glutamine, and antibiotics. Cell line characterization and passaging for $\sim 3$ months were performed prior to purchase. Therefore, we did not carry out reauthentication of the cell lines. ATCC used Short Tandem Repeat (STR) profiling to detect the misidentified, cross-contaminated, or genetically drifted cells. A
Promega PowerPlex ${ }^{\circledR}$ 18D System was used to amplify 17 STR loci plus amelogenin. Human umbilical vein endothelial cells (HUVECs) were obtained from the Cell Bank, Chinese Academy of Sciences (Shanghai, China). All cell lines were maintained at $37^{\circ} \mathrm{C}$ in a humidified chamber supplemented with $5 \% \mathrm{CO}_{2}$.

Oligonucleotide and plasmid transfection. The miRNA mimics (miR-195, cat. no. miR10000461-1-5) and negative control miRNA mimics (miR-NC, cat. no. miR01201-1-5) used for transient transfection were designed and synthesized by RiboBio (Guangzhou, China). The PRR11 coding sequence (without the 3' UTR) was cloned into a pCDNA3.1 (+)-Vector (cat. no. V790-20; Invitrogen, USA), while a blank vector was used as a negative control. Short interfering RNA (siRNA) against PRR11 (si-PRR11) and negative control siRNA with non-specific sequences (si-NC) were synthesized by Sigma-Aldrich (USA). The targeting sequences of the si-PRR11 were as follows: 5'-CUGCAUAACCCAGAG UUUAdTdT-3' (sense) and 5'-UAAACUCUGGGUUAU GCAGdTdT-3' (antisense). The sequences of the si-NC were as follows: 5'-UUCUCCGAACGUGUCACGUTT-3' (sense) and 5'-ACGUGACACGUUCGGAGAATT-3' (antisense). Cells were transfected with the miRNA mimics, siRNA and pCDNA3.1(+)-PRR11 using Lipofectamine 2000 Reagent (cat. no. 11668019; Invitrogen, USA)according to the manufacturer's protocol. At $48 \mathrm{~h}$ after transfection, the cells were used in the cell cycle, CCK-8, RNA extraction and western blotting assays.

Knockdown of PRR11 by lentiviral shRNA in DU145 andLNCAP cells. Packaging of lentiviral particles was performed as follows: Briefly, three lentivirus expression plasmids containing siRNA against PRR11 were constructed by GeneChem Corporation (Shanghai, China) and were used to infect DU145 and LNCaP cells in the presence of $6 \mu \mathrm{g} / \mathrm{ml}$ Polybrene: PRR11-shRNA1: 5'-TCAGATGGATCTGCGGAAACTTCCTGTCAGATTTCC GCAGATCCATCTGA-3'; PRR11-shRNA2: GGATCTGCG GAAACTGCTTCTTCCTGTCAGAAAGCAGTTTCCGCAG ATCC; and PRR11-shRNA3: CCTAGAAGCCCAACTCCA ACTTCCTGTCAGATTGGAGTTGGGCTTCTAGG. Infected cells were selected for using puromycin, and the knockdown of PRR11 was confirmed via western blotting using anti-PRR11 antibody (cat. no. HPA023923; Sigma-Aldrich, USA). One of the PRR11-shRNAs was chosen for further experiments.

Microarray analysis. Total RNA was extracted using TRIzol reagent (cat. no. 15596-018; Life Technologies, Carlsbad, CA, USA) following the manufacturer's instructions, and RNA integrity was checked against an RIN threshold in an Agilent Bioanalyzer 2100 (Agilent Technologies, Santa Clara, CA, USA). Qualified total RNA was further purified with an RNeasy Micro kit (cat. no. 74004; Qiagen, GmBH, Germany) and RNase-Free DNase Set (cat. no. 79254; Qiagen). Total RNA was then amplified, labeled and purified using a GeneChip 3'IVT Express Kit (cat. no. 901229; Affymetrix, Santa Clara, CA, USA) following the manufacturer's instructions to obtain biotin-labeled cRNA. For array hybridization, the hybridization procedure was performed using a GeneChip ${ }^{\circledR}$ Hybridization, Wash and Stain Kit (cat. no. 900720; Affymetrix) in a 
Hybridization Oven 645 (cat. no. 00-0331-220V) and Fluidics Station 450 (cat. no. 00-0079; Affymetrix) following the manufacturer's instructions. For data acquisition, slides were scanned with a GeneChip ${ }^{\circledR}$ Scanner 3000 (cat. no. 00-00212; Affymetrix) using Command Console Software 3.1 (Affymetrix) at default settings. Raw data were normalized by the MAS 5.0 algorithm using Gene Spring Software 11.0 (Agilent Technologies).

Bioinformatic miRNA target prediction. The online program TargetScan (release 6.2) (23) was used to predict potential target genes for miR-195.

$R T-q P C R$. The expression levels of miR-195 and PRR11 mRNA in the PCa cell lines were detected by RT-qPCR analysis according to the protocol in our previous study (24). The oligonucleotide sequences (5'-3') of the primers used in the present study were as follows: PRR11 (F, CCTGCT AGCTACATTTACA, R, GAATGGTCA AGTCATTTA GC); GAPDH (F, CATGGGTGTGAACCATGAGAAGTA, R, CAGTAGAGGCAGGGATGATGTTCT); hsa-miR195-5p (cat. no. HmiRQP0283; GeneCopoeia, USA) and U6 (cat. no. HmiRQP9001; GeneCopoeia, USA).

Western blot analysis. The expression levels of PRR11 protein in the PCa cell lines were detected by western blot analysis according to the protocol in our previous study (24). The antibodies used in the present study were as follows: Anti-PRR11 (polyclonal rabbit, cat. no. HPA023923; Sigma-Aldrich, USA), anti-GAPDH (HRP-conjugated monoclonal mouse, cat. no. KC-5G5; KangChen Bio-Tech, Shanghai, China).

Immunohistochemistry. The expression pattern and subcellular localization of PRR11 protein in clinical PCa tissues, and of CD31 and Ki-67 in the subcutaneous tumor xenografts of nude mice, were detected by immunohistochemistry. The specimens were fixed in $10 \%$ neutral buffered formalin and subsequently embedded in paraffin. The paraffin-embedded tissues were cut to a thickness of $4 \mu \mathrm{m}$ and deparaffinized with xylene, and then rehydrated for further peroxidase (DAB) immunohistochemistry staining employing a Dako EnVision System (Dako Diagnostics, Switzerland). For this staining assay, following a brief proteolytic digestion and peroxidase blocking of the tissue slides, the slides were incubated overnight at $4^{\circ} \mathrm{C}$ with the abovementioned anti-PRR11 antibody at a dilution of 1:600, along with anti-CD31 (rabbit monoclonal antibody; cat. no. ZA-0568; ZSGB-BIO, China) at a dilution of 1:200, and anti-Ki-67 (rabbit monoclonal antibody; cat. no. ZA-0502; ZSGB-BIO, China) at a dilution of 1:200. After washing, peroxidase-labeled polymer and chromogen substrate were used to visualize the staining of the proteins of interest. In each immunohistochemistry run, negative controls were included by omitting the primary antibody.

Following hematoxylin counterstaining, immunostaining was scored by two independent experienced pathologists who were blinded to the clinicopathological data and clinical outcomes. The scores of the two pathologists were compared and any discrepant scores were reviewed through re-examination of the staining by both pathologists to achieve a consensus score. Scores were assigned by evaluating the immunolabeling of tumor cells. The number of positively stained cells in 10 representative microscopic fields was counted, along with the percentage of positive cells. Given the heterogeneity of the target protein staining, tumor specimens were scored in a semi-quantitative manner. The scoring system based on the percentage of immunoreactive tumor cells was as follows: $0(0-5 \%), 1(6-25 \%), 2(26-50 \%), 3(51-75 \%)$ and $4(>75 \%)$. Additionally, staining intensity was visually scored and stratified as follows: 0 (negative), 1 (weak), 2 (moderate) and 3 (strong). Final immunoreactivity scores (IRS) for PRR11 and $\mathrm{Ki}-67$ were then obtained for each sample by multiplying the percentage of positive cells by the intensity score. Vasculature density in the tumor xenografts was also determined from the number of CD31-positive vessels.

Generation of the in vivo xenograft model. For the in vivo tumor formation assays, DU145 or LNCaP cells transfected with lentivirus expression plasmid containing PRR11-shRNA or negative control (scramble) were trypsinized and suspended in PBS. Subsequently, the cells were subcutaneously injected into the right flank of each nude mouse (8 mice per group); DU145 cells were injected with $0.2 \mathrm{ml} \mathrm{PBS}$ at a concentration of $2.5 \times 10^{7}$ cells $/ \mathrm{ml}$, while $\mathrm{LNCaP}$ cells were injected as a mixture of $0.1 \mathrm{ml}$ PBS at a concentration of $5 \times 10^{8}$ cells $/ \mathrm{ml}$ and an equal volume of Matrigel (cat. no. 356234; BD Biosciences). The tumor sizes were measured at 2-day intervals as soon as the tumors were measurable, and the tumor volumes were calculated as follows: $\mathrm{V}\left(\mathrm{mm}^{3}\right)=$ width $\left(\mathrm{mm}^{2}\right) \times$ length $(\mathrm{mm}) / 2$. On day 42, all mice in the LNCaP and DU145 groups were sacrificed.

Luciferase reporter assay. The expression of the target gene of miR-195 was evaluated in LNCaP cells by a luciferase reporter assay. The putative miR-195 complementary site in the 3' UTR of PRR11 mRNA (NCBI reference sequence: NM_018304.3; 3' UTR-1: 3490-3496 and 3' UTR-2: 4827-4833) or a mutant sequence was cloned into a psiCHECK-2 luciferase reporter vector (Promega, Madison, WI, USA). LNCaP cells were co-transfected with $50 \mathrm{nM}$ miR-195 mimic or miR-NC and $0.5 \mu \mathrm{g}$ of psi-PRR11-3' UTR-1-WT, psi-PRR11-3' UTR-2-WT, psi-PRR11-3' UTR-1-MUT or psi-PRR11-3' UTR-2-MUT. Cells were collected $48 \mathrm{~h}$ after transfection and analyzed with a Dual-Luciferase Reporter Assay System (Promega). The firefly and Renilla luciferase signals were detected with a GloMax fluorescence reader (Promega), and the Renilla luciferase signal was normalized to the firefly luciferase signal.

Cell viability assay. For cell viability assays, $2 \times 10^{3}$ cells were seeded in 96-well plates and cultured for 24, 48 and $72 \mathrm{~h}$. Cells were then incubated with $20 \mu \mathrm{l}$ of CCK-8 solution (cat. no. C0038; Beyotime, China) for $4 \mathrm{~h}$ at $37^{\circ} \mathrm{C}$. The absorbance was measured at a wavelength of $495 \mathrm{~nm}$ with a spectrophotometer, and data were expressed as means \pm SD of three independent experiments.

HUVEC tube formation assay. A total of $200 \mu 1$ human umbilical vein endothelial cells (HUVECs; $2 \times 10^{4}$ cells) were seeded in 48-well plates containing $200 \mu \mathrm{l}$ BD Matrigel Basement Membrane Matrix (cat. no. 356234; BD Biosciences) for $8-12 \mathrm{~h}$ at $37^{\circ} \mathrm{C}$. LNCaP and DU145 cells transfected with 
oligonucleotide and/or plasmid were seeded in the upper Transwell chambers (cat. no. 3495; Corning Incorporated, Corning, NY, USA), in which the conditioned medium permeated through the $0.4-\mu \mathrm{m}$ micropores to the Matrigel, which established a non-contact co-culture system. Images were acquired with a phase-contrast microscope. The numbers of tubes were counted in three individual wells and presented as the mean $\pm \mathrm{SD}$.

Cell cycle analysis. A flow cytometry assay (kit cat. no. KGA511) was performed to assess the cell cycle distributions of the DU145 and LNCaP cells. At $48 \mathrm{~h}$ after cell transfection, attached and suspended cells were harvested with a pipette, washed once with $1 \mathrm{ml} \mathrm{PBS}$, and resuspended in $500 \mu \mathrm{l}$ PBS containing $50 \mu \mathrm{g} / \mathrm{ml}$ propidium iodide (PI). RNase A $(100 \mu \mathrm{g} / \mathrm{ml})$ and $0.2 \%$ Triton $\mathrm{X}-100$ were then added to the cells, which was followed by incubation at $4^{\circ} \mathrm{C}$ for $30 \mathrm{~min}$ in the dark prior to flow cytometric analysis (BD FACSCaliber). Data analysis was performed using ModFit software (Verity Software House, Inc., Topsham, ME, USA.).

Statistical analysis. Continuous variables are expressed as means \pm SD. SPSS version 20.0 for Windows (SPSS, Inc., IL, USA) and SAS 9.1 (SAS Institute, Cary, NC, USA) were used for all statistical analyses, which were performed by two independent biostatisticians. The RT-qPCR and western blot data were analyzed by Wilcoxon signed-rank tests. The Fisher's exact test was used for any $2 \times 2$ tables and the Pearson $\chi^{2}$ test was used for non- $2 \times 2$ tables. Mann-Whitney U and Kruskal-Wallis $\mathrm{H}$ tests were performed to examine the associations between PRR11 expression and the clinicopathological characteristics of PCa patients in the Taylor cohort. The Kaplan-Meier method was used for survival analysis, and Cox regression analysis was used for univariate and multivariate analyses. Finally, Spearman correlations were calculated for the expression levels of miR-195 and PRR11 in the Taylor cohort. A P-value of $<0.05$ was considered to indicate a statistically significant difference.

\section{Results}

Upregulation of miR-195 suppresses angiogenesis and proliferation in vitro. In our previous study, we found that miR-195 suppressed invasion and migration while promoting apoptosis in PCa cells (21). To verify the biological role of miR-195 in angiogenesis and proliferation in vitro, we used LNCaP $(\mathrm{P}<0.001)$ and DU145 $(\mathrm{P}<0.001)$ PCa cell lines overexpressing miR-195 mimics (miR-195 group) or negative control miR (miR-NC group) via transient transfection. RT-qPCR analysis confirmed that transient transfection of the cell lines was successfully established (Fig. 1A). To investigate whether miR-195 has biological effects on tumor angiogenesis, HUVEC tube formation assays were carried out. The results indicated that the tube formation of HUVECs was strongly inhibited by the conditioned media from DU145 and LNCaP cells overexpressing miR-195 when compared with their negative control (miR-NC) media (Fig. 1B). Notably, the relative tube-forming abilities of miR-195-overexpressing DU145 and LNCaP cells, determined by comparing the number of complete tubes per field, were significantly increased when compared with their miR-NC counterparts $(\mathrm{P}=0.017$ and $\mathrm{P}=0.005$, respectively; Fig. 1C). Moreover, in both the DU145 and LNCaP cells, overexpression of miR-195 strongly inhibited cell proliferation (Day 4: $\mathrm{P}=0.008$ and $\mathrm{P}=0.006$, respectively; Fig. 1D) compared with the controls.

Microarray analysis of differentially expressed $m R N A s$ induced by miR-195. Since miRNAs in most cases only cause modest decreases in protein translation, the miRNA-mediated regulation of proteins with long half-lives may not be detected by measuring steady-state protein levels using standard proteomic quantification (25), which was used in our previous study (21). Therefore, to solve the shortage of the standard proteomic quantification and identify more novel targets of miR-195 in PCa, we performed microarray analysis on the same cells (LNCaP cells overexpressing miR-195 or miR-NC) to detect miR-195-induced changes in mRNA levels. As shown in Fig. 2A, a total of 153 genes differentially regulated with fold changes $\leq-1.5$ or $\geq 1.5$ (miR-195 vs. miR-NC) were identified in at least two independent experiments. miRNAs typically destabilize post-transcriptional mRNAs. Thus, as expected, among the 153 genes, there were 138 (90.2\%) downregulated genes and $15(9.8 \%)$ upregulated genes. We then investigated the molecular roles of the differentially expressed genes regulated by miR-195 by using Ingenuity Pathway Analysis (IPA). Among the pathways enriched for differentially expressed genes, there were a number of tumor-related pathways, including mTOR signaling, EIF-2 signaling, cell cycle signaling, and remodeling of epithelial adherens junctions signaling (Fig. 2B), which all have broad effects on cell behavior. These results suggested that the biological pathways and functions regulated by miR-195 were closely associated with $\mathrm{PCa}$ progression.

PRR11 is a direct target of miR-195. We additionally used an miRNA target prediction program (TargetScan) to predict the top 10 candidate targets of the downregulated genes identified by microarray. TFEC, ZFHX3, PRR11, GCC2, RPS6KB1 and ENAH were predicted, which demonstrated that miR-195 may bind to the 3' UTR sequences of these genes (Fig. 3A). We further found that PRR11 and RPS6KB1 were involved in the top 10 enriched pathways (data not shown). RPS6KB1 is a critical component of mTOR signaling and was identified as a target gene of miR-195 in our previous study (21). Meanwhile, the present results identified PRR11 as a key component in cell cycle signaling, implying that PRR11 might also be an important mediator of the biological role of miR-195 in PCa.

We continued to investigate the relationship between miR-195 expression and PRR11 mRNA expression in the Taylor cohort, comprised of mRNA and miRNA expression profiles for 113 primary PCa tissues (22). The results demonstrated that PRR11 expression was negatively correlated with miR-195 expression ( $\mathrm{r}=-0.355, \mathrm{P}<0.001$; Fig. 3B), which corresponded with the targeting data for miR-195.

More notably, we found that miR-195 downregulation combined with PRR11 upregulation was associated with aggressive clinicopathological features and poor prognosis of PCa patients in the Taylor cohort. As shown in Table I, miR-195 downregulation and PRR11 upregulation were frequently observed in cases presenting with the most aggressive features, 


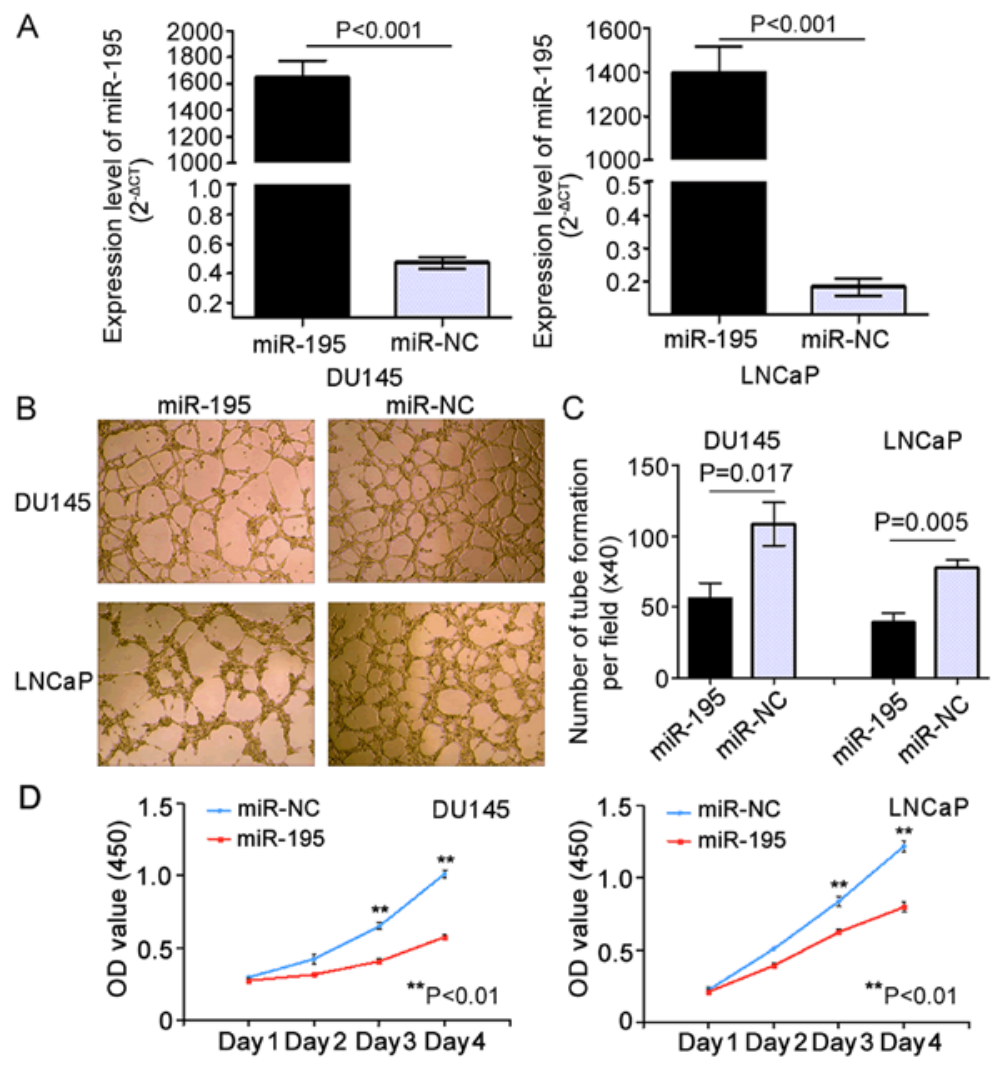

Figure 1. Overexpression of miR-195 suppresses the proliferation of LNCaP and DU145 cells and inhibits human umbilical vein endothelial cell (HUVEC) tube formation in vitro. (A) miR-195 levels were determined by RT-qPCR at $48 \mathrm{~h}$ after transient transfection of DU145 and LNCaP cells with miR-195 mimics. miR-195 expression (miR-195/U6) was calculated as fold change relative to the negative control (NC). (B) HUVEC tube formation was inhibited by the addition of conditioned media from DU145 and LNCaP cells transfected with miR-195 mimics. (C) The number of complete tubes per field (x40) was calculated. (D) Enforced expression of miR-195 inhibited the proliferation of DU145 and LNCaP cells. Statistical analysis was performed on the results from three independent experiments. Data are presented as means $\pm \mathrm{SD}$. ${ }^{* *} \mathrm{P}<0.01$ compared with the negative control.

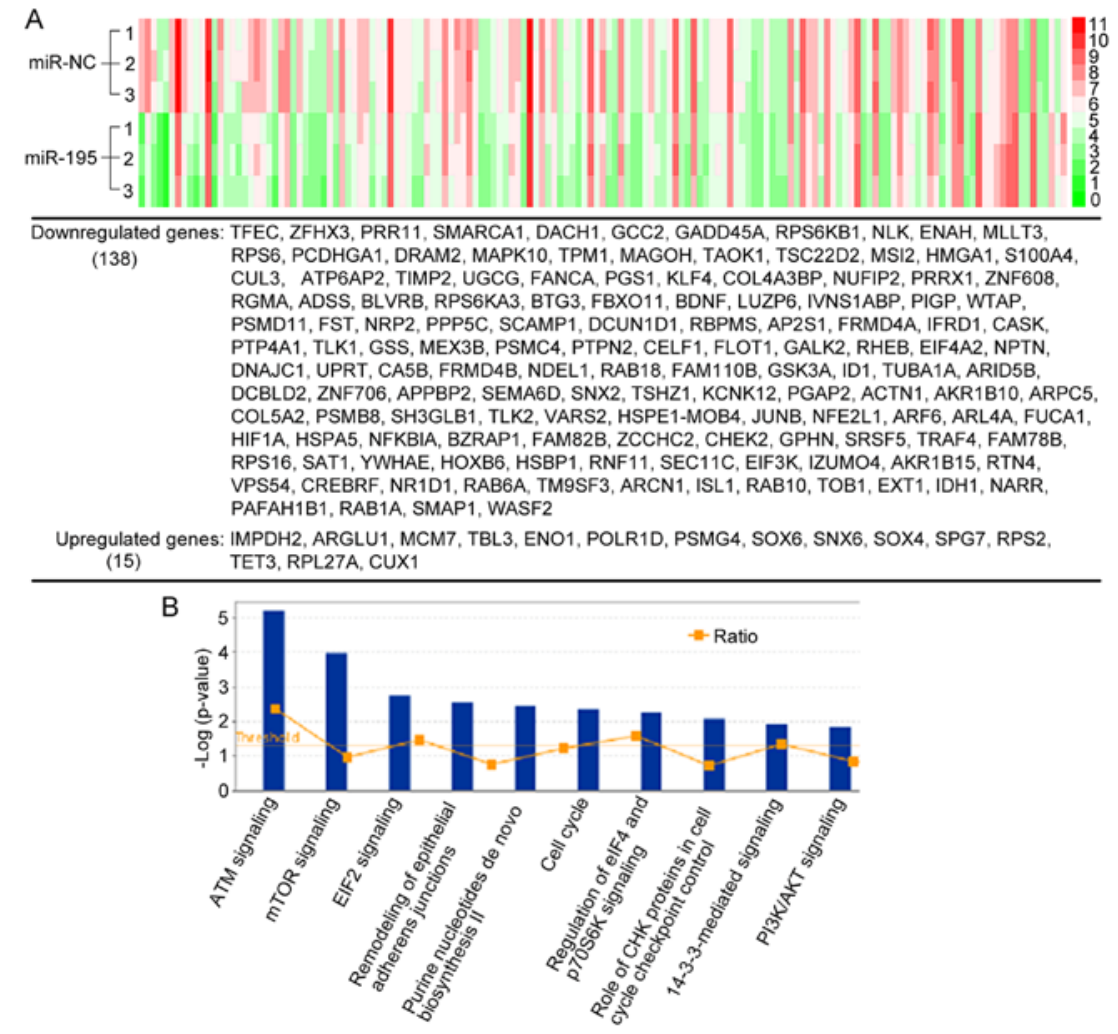

Figure 2. Analysis of RNA-based microarray following miR-195 overexpression. (A) Supervised hierarchical clustering of the genes significantly differentially expressed after miR-195 overexpression in LNCaP cells (fold changes $\leq-1.5$ or $\geq 1.5$ ). (B) Top 10 enriched KEGG pathways associated with the differentially expressed genes induced by miR-195. 
A

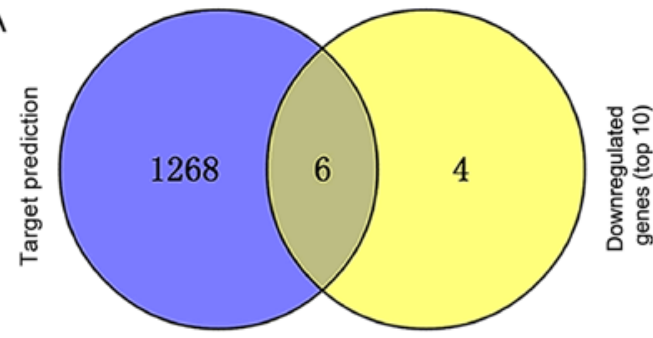

B

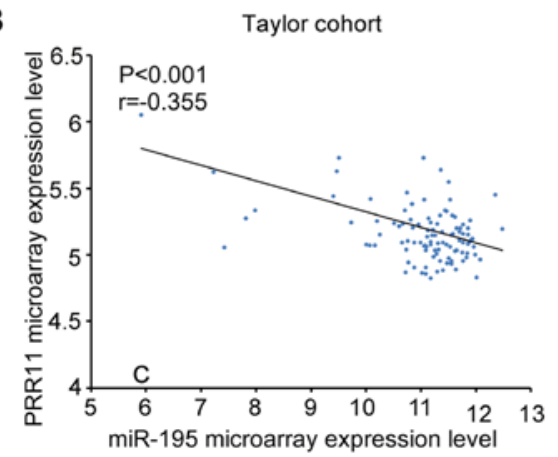

。

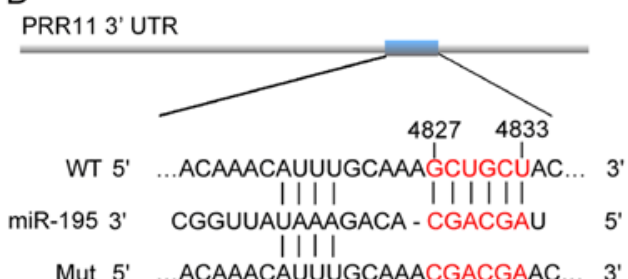

$\mathrm{F}_{\mathrm{PRR} 113^{\prime} \text { UTR }}$

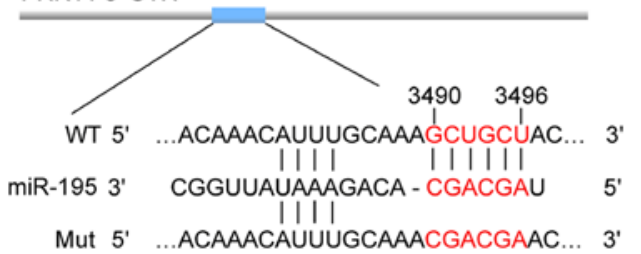

C

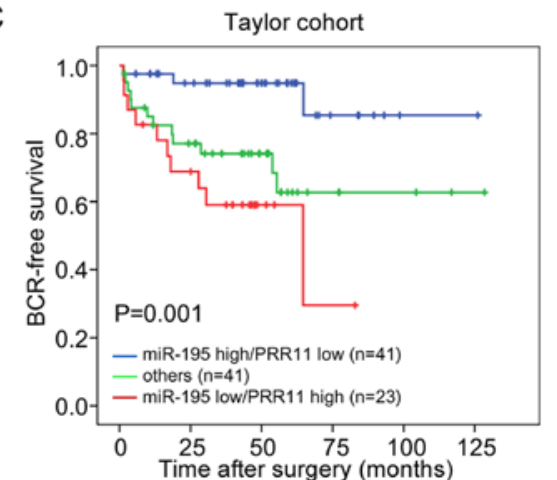

$\mathrm{E}$

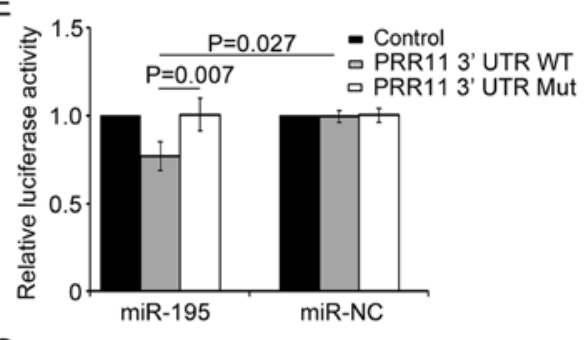

G

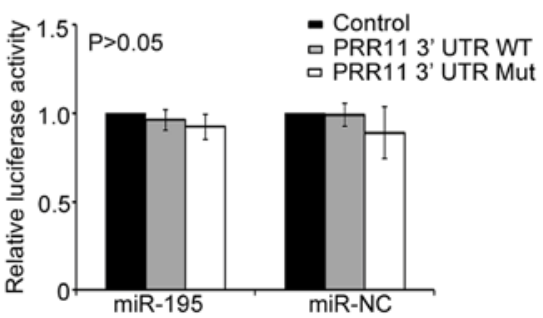

Figure 3. PRR11 is a direct target of miR-195. (A) Six genes were shared between the results of the TargetScan miRNA target prediction and RNA microarray following miR-195 overexpression. (B) Spearman correlation analysis clearly indicated an inverse relationship between PRR11 and miR-195 expression in the Taylor cohort $(\mathrm{r}=-0.355, \mathrm{P}<0.001)$. (C) miR-195 expression level combined with PRR11 expression level was able to stratify patients into different groups according to BCR-free survival. (D) RNA sequence alignment of the 3' UTR of PRR11 mRNA indicating a complementary site for the seed region of miR-195 at 4827-4833 bp. PRR11-mut was a mutant sequence with substitutions in the complementary region (negative control). (E) Luciferase activity was decreased after transfection of psi-PRR11-3' UTR-2-WT into miR-195-transfected LNCaP cells. (F) RNA sequence alignment of the 3' UTR of PRR11 mRNA indicating a complementary site for the seed region of miR-195 at 3490-3496 bp. (G) Luciferase activity was unchanged after transfection of psi-PRR11-3' UTR-1-WT into miR-195-transfected LNCaP cells. Data are presented as means \pm SD.

including those with higher Gleason scores $(\mathrm{P}=0.005)$, higher risk of metastasis $(\mathrm{P}<0.001)$ and $\mathrm{BCR}(\mathrm{P}=0.003)$. By contrast, miR-195 upregulation and PRR11 downregulation often occurred in the most indolent tumors, while other regulation states, including simultaneous upregulation or downregulation of miR-195 and PRR11, could be seen in the patients with intermediate risk of progression. Kaplan-Meier analysis also indicated that miR-195 expression combined with PRR11 expression could significantly stratify patients into three groups based on BCR-free survival time ( $\mathrm{P}=0.001$; Fig. 3C). Notably, patients with low miR-195 and high PRR11 expression were likely to have the shortest BCR-free survival time. Additionally, univariate and multivariate Cox regression analysis revealed that miR-195 expression combined with PRR11 expression served as an independent predictor for BCR-free survival ( $\mathrm{P}=0.001$ and $\mathrm{P}=0.034$, respectively; Table II). These results indicated that PRR11, in an opposing manner to miR-195, might act as a promotive factor in PCa progression. Thus, PRR11 may be a potential target of miR-195 in PCa.

According to the TargetScan prediction, two putative binding sites for miR-195 were found in the 3' UTR of PRR11 at 4827-4833 and 3490-3496 bp (Fig. 3D and F). To confirm these predictions, a luciferase reporter assay was carried out in LNCaP cells. In this assay, relative luciferase activity was markedly reduced in cells co-transfected with psi-PRR11-3' UTR-2-WT luciferase reporter and miR-195 mimic compared with negative control cells $(\mathrm{P}=0.027$; Fig. 3E). In contrast, the expression of the lucif- 
Table I. Association of miR-195/PRR11 expression and the clinicopathological features of the prostate cancer (PCa) patients.

\begin{tabular}{|c|c|c|c|c|c|}
\hline & \multirow[b]{2}{*}{$\mathrm{N}$} & \multicolumn{3}{|c|}{ hsa-miR-195/PRR11 } & \multirow[b]{2}{*}{ P-value } \\
\hline & & $\begin{array}{c}\text { miR-195 high/PRR11 } \\
\text { low }(\mathrm{n}=42)\end{array}$ & Others $(\mathrm{n}=42)$ & $\begin{array}{c}\text { miR-195 low/PRR11 } \\
\text { high }(\mathrm{n}=27)\end{array}$ & \\
\hline Mean age (years) & 111 & $58.57 \pm 6.17$ & $57.34 \pm 8.07$ & $59.48 \pm 8.45$ & 0.495 \\
\hline \multicolumn{6}{|c|}{ Preoperative PSA (ng/ml) } \\
\hline$<4$ & 26 & $9(34.6)$ & $14(53.8)$ & $3(11.5)$ & \multirow[t]{2}{*}{0.126} \\
\hline$\geq 4$ & 83 & $33(39.8)$ & $28(33.7)$ & $22(26.5)$ & \\
\hline \multicolumn{6}{|l|}{ Gleason score } \\
\hline$<8$ & 87 & $38(43.7)$ & $34(39.1)$ & $15(17.2)$ & \multirow[t]{2}{*}{0.005} \\
\hline$\geq 8$ & 17 & $3(17.6)$ & $5(29.4)$ & $9(52.9)$ & \\
\hline \multicolumn{6}{|l|}{ Clinical stage } \\
\hline$<\mathrm{T} 2 \mathrm{~A}$ & 64 & $23(35.9)$ & $24(37.5)$ & $17(26.6)$ & \multirow[t]{2}{*}{0.456} \\
\hline$\geq \mathrm{T} 2 \mathrm{~A}$ & 43 & $18(41.9)$ & $18(41.9)$ & $7(16.3)$ & \\
\hline \multicolumn{6}{|l|}{ Pathological stage } \\
\hline $\mathrm{T} 2 \mathrm{~A}-\mathrm{T} 2 \mathrm{C}$ & 69 & $31(44.9)$ & $24(34.8)$ & $14(20.3)$ & \multirow[t]{2}{*}{0.197} \\
\hline T3A-T4 & 37 & $10(27)$ & $17(45.9)$ & $10(27)$ & \\
\hline \multicolumn{6}{|l|}{ Metastasis } \\
\hline Negative & 93 & $40(43)$ & $37(39.8)$ & $16(17.2)$ & \multirow[t]{2}{*}{$<0.001$} \\
\hline Positive & 18 & $2(11.1)$ & $5(27.8)$ & $11(61.1)$ & \\
\hline \multicolumn{6}{|c|}{ Biochemical recurrence } \\
\hline Negative & 80 & $38(47.5)$ & $29(36.3)$ & $13(16.3)$ & \multirow[t]{2}{*}{0.003} \\
\hline Positive & 25 & $3(12)$ & $12(48)$ & $10(40)$ & \\
\hline \multicolumn{6}{|l|}{ Overall survival } \\
\hline Alive & 99 & $38(38.4)$ & $40(40.4)$ & $21(21.2)$ & \multirow[t]{2}{*}{0.07} \\
\hline Died & 12 & $4(33.3)$ & $2(16.7)$ & $6(50.0)$ & \\
\hline
\end{tabular}

PSA, prostate-specific antigen.

Table II. Prognostic value of miR-195/PRR11 expression for the biochemical recurrence-free survival in univariate and multivariate analyses by Cox regression.

\begin{tabular}{|c|c|c|c|c|}
\hline & \multicolumn{2}{|c|}{ Univariate analysis } & \multicolumn{2}{|c|}{ Multivariate analysis } \\
\hline & $\mathrm{HR}(95 \% \mathrm{CI})$ & $\mathrm{P}$-value & $\mathrm{HR}(95 \% \mathrm{CI})$ & P-value \\
\hline Age (years) & $1.04(0.98-1.09)$ & 0.186 & $1.02(0.96-1.08)$ & 0.581 \\
\hline Clinical tumor stage & $0.85(0.37-1.94)$ & 0.700 & $0.80(0.32-2.02)$ & 0.641 \\
\hline Pathological tumor stage & $5.83(2.50-13.56)$ & $<0.001$ & $2.70(0.92-7.93)$ & 0.070 \\
\hline Preoperative PSA & $2.45(0.73-8.22)$ & 0.366 & $1.30(0.35-4.80)$ & 0.700 \\
\hline Gleason score & $11.97(5.31-27.01)$ & $<0.001$ & $6.06(2.07-17.71)$ & 0.001 \\
\hline miR-195/PRR11 & $2.59(1.51-4.42)$ & 0.001 & $1.98(1.05-3.71)$ & 0.034 \\
\hline
\end{tabular}

erase reporter containing a mutated sequence of the PRR11 fragment (psi-PRR11-3' UTR-2-MUT) was not affected by co-transfection with hsa-miR-195 mimics. Meanwhile, relative luciferase activity was not significantly changed in cells co-transfected with psi-PRR11-3' UTR-1-WT luciferase reporter and miR-195 mimic relative to the negative control cells $(\mathrm{P}>0.05$; Fig. 3G). These results indicated that the sequence at $4827-4833$ bp in the $3^{\prime}$ UTR of PRR11 was the complementary site for the miR-195 seed region, and further demonstrated that PRR11 is a direct target of miR-195. 

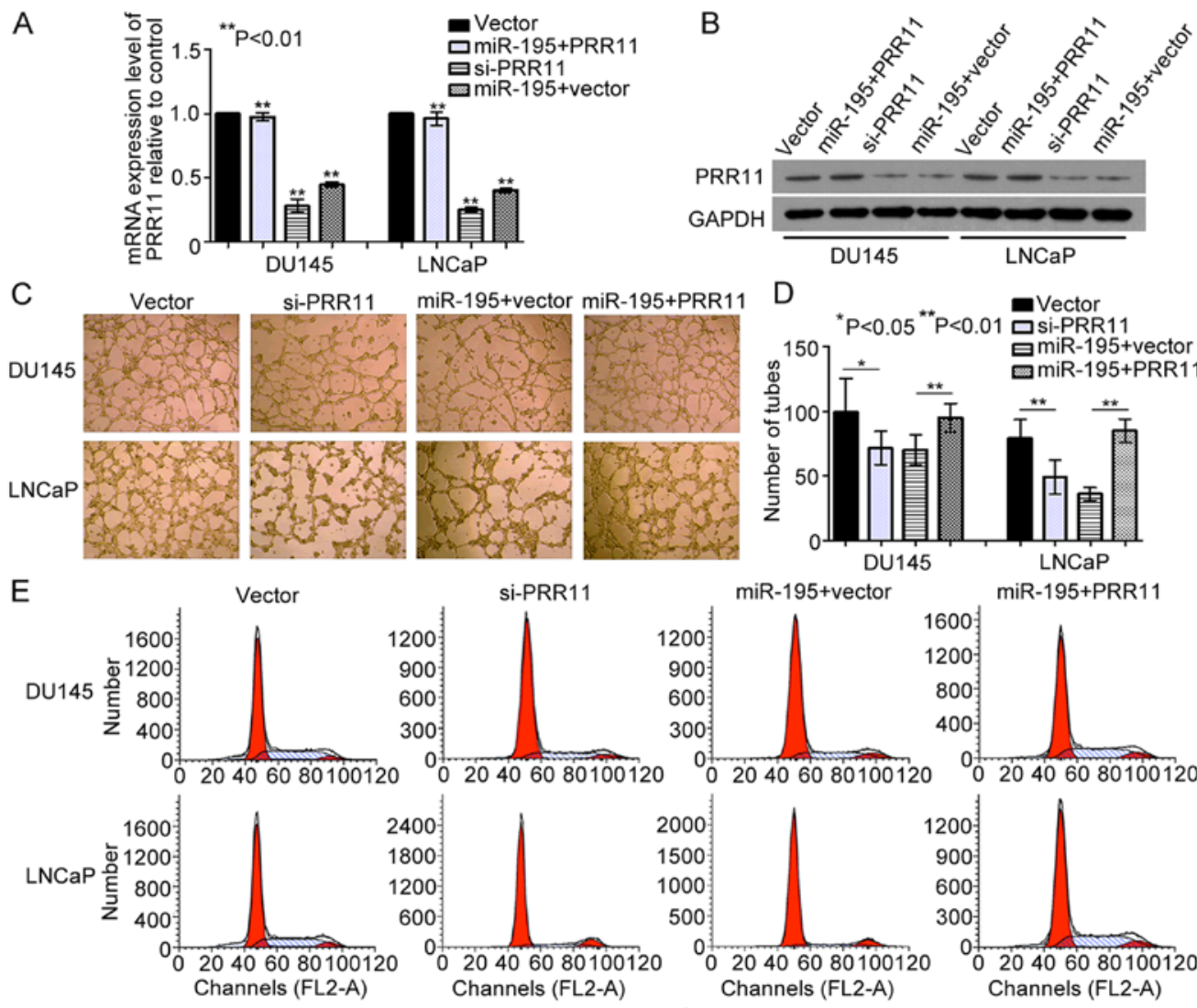

$\mathrm{F}$
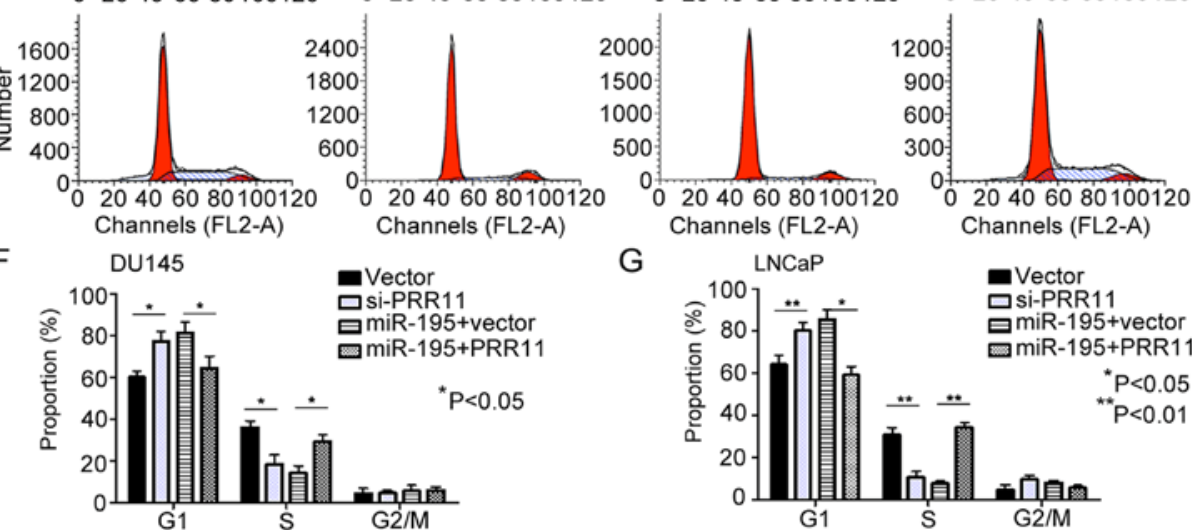

G
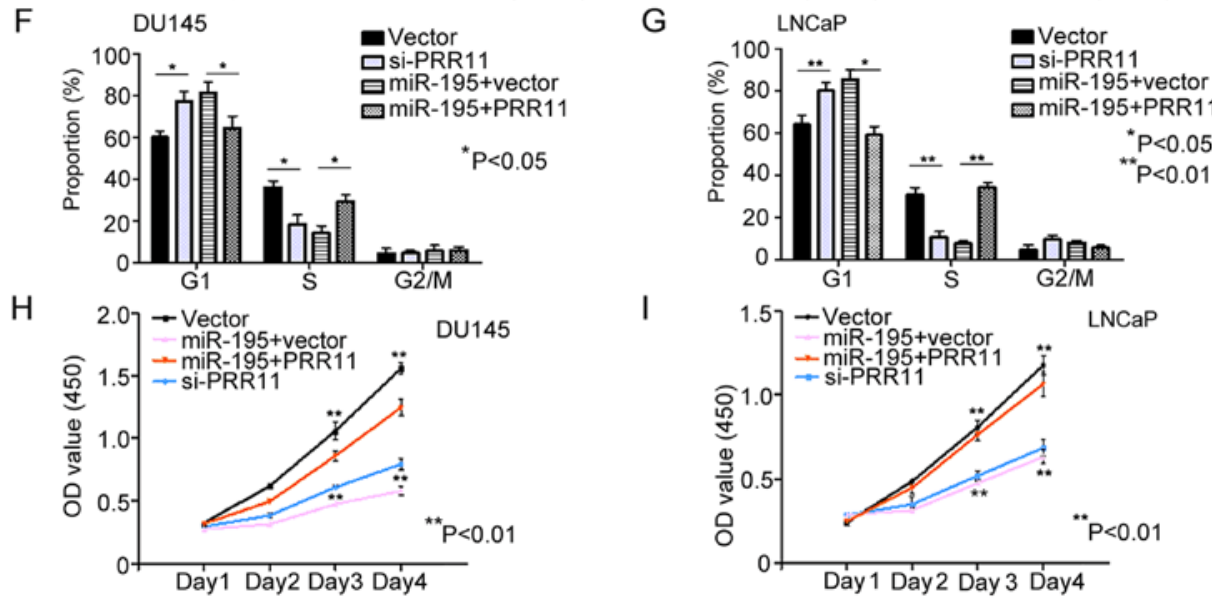

I

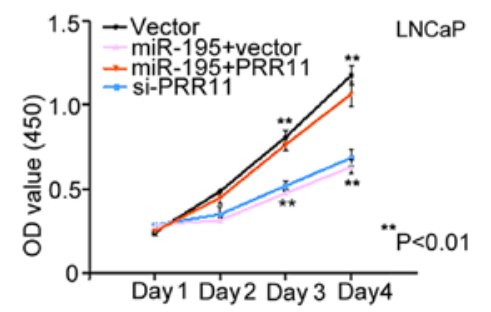

Figure 4. miR-195 exerts its tumor suppressive role by downregulating PRR11 expression. (A and B) Endogenous PRR11 expression levels were detected by RT-qPCR and western blotting in DU145 and LNCaP cells transfected with miR-195 mimic in the presence of PRR11, with miR-195 mimic in the presence of vector control, with PRR11 siRNA or with vector control for 48 h. (C-I) Expression of PRR11 using a construct lacking the 3' UTR of PRR11 abrogated the biological effects associated with miR-195 overexpression, and knockdown of endogenous PRR11 expression with siRNA generated similar effects as those induced by miR-195 on HUVEC tube formation, cell cycling and cell proliferation. Data were obtained from three independent experiments and are presented as means $\pm \mathrm{SD} .{ }^{*} \mathrm{P}<0.05,{ }^{* *} \mathrm{P}<0.01$ compared with control.

miR-195 exerts its tumor suppressive role partially by downregulating PRR11 expression. The direct targeting of PRR11 by miR-195 was evaluated in the PCa cell lines DU145 and LNCaP. We found that the mRNA and protein levels of PRR11 were significantly decreased by miR-195 overexpression in DU145 and LNCaP cells (both $\mathrm{P}<0.001$; Fig. 4A and B). Subsequently, we knocked down the endogenous expression of PRR11 in DU145 and LNCaP cells with PRR11 siRNA (both $\mathrm{P}<0.001$; Fig. 4A and B). Compared with the negative controls, knockdown of PRR11 in the DU145 and LNCaP cells inhibited the tube formation abilities of HUVECs $(\mathrm{P}=0.046$ and
$\mathrm{P}=0.006$, respectively; Fig. 4C and D), suppressed cell cycling (G1 phase: both $\mathrm{P}=0.045$; $\mathrm{S}$ phase: both $\mathrm{P}=0.001$; Fig. $4 \mathrm{E}-\mathrm{G}$ ) and suppressed cell proliferation (Day 4: $\mathrm{P}=0.003$ and $\mathrm{P}=0.005$, respectively; Fig. $4 \mathrm{H}$ and I). Furthermore, we transfected cells with pCDNA3.1 (+)-vectors expressing PRR11 without its 3' UTR. As shown in Fig. 4A and B, the endogenous PRR11 expression levels were detected by qRT-PCR and western blot analysis in the DU145 and LNCaP cells transfected with the miR-195 mimics in the presence of PRR11 or vector control for $48 \mathrm{~h}(\mathrm{P}<0.001$ and $\mathrm{P}<0.002$, respectively). In turn, restoration of PRR11 expression markedly attenuated the effects of 


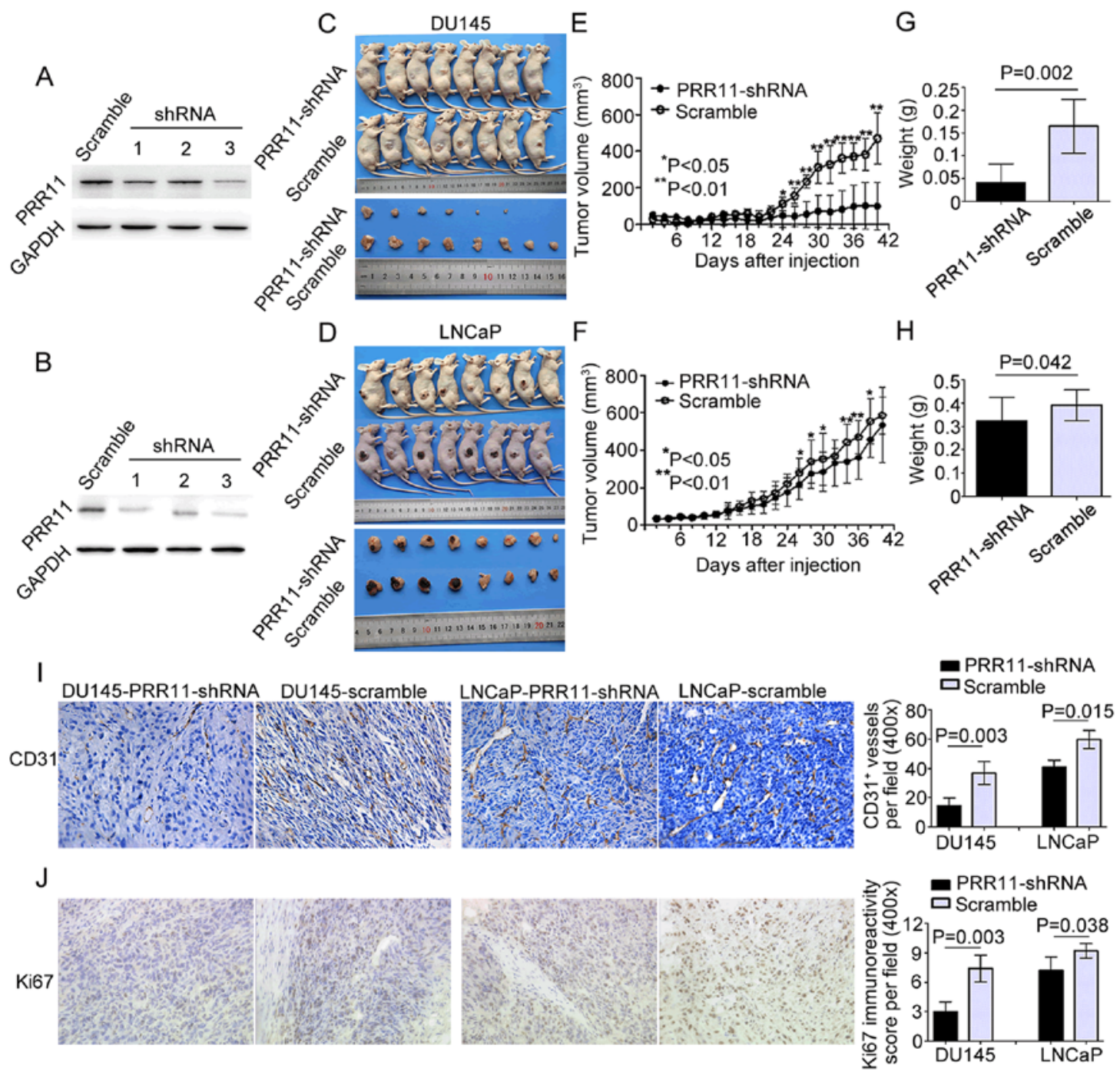

Figure 5. Knockdown of PRR11 suppresses tumor growth and angiogenesis in vivo. (A and B) Western blotting showed that PRR11 expression in PCa cells was inhibited by three lentivirus expression plasmids containing small interfering RNAs against PRR11. The cells transfected with the third lentivirus expression plasmid were used in subsequent experiments. (C and D) Knockdown of PRR11 by the lentivirus-shPRR11 vector in DU145 and LNCaP cells inhibited subcutaneous tumor growth over the 42-day monitoring period after tumor cell injection. (E-H) The tumor growth curves are shown. Knockdown of PRR11 suppressed the growth of tumor nodules and reduced the weight of tumors in the PRR11-shRNA groups on day 42 compared with the control groups (scramble). (I and J) Immunochemistry analysis of the tumor xenografts. CD31 stained the cytomembrane or cytoplasm of pan-endothelial cells undergoing angiogenesis. Ki67 stained the nucleus of proliferative PCa cells (shown in the fields at a magnification of x400). The CD31 staining results indicated that PRR11 downregulation reduced angiogenesis in tumor xenografts compared with control tumor xenografts. The Ki67 staining results indicated that the tumor xenografts established by cells with low expression of PRR11 expressed less Ki67 protein. The results are presented as means \pm SD. ${ }^{*} \mathrm{P}<0.05,{ }^{* *} \mathrm{P}<0.01$ compared with the negative control.

miR-195 on HUVEC tube formation $(\mathrm{P}=0.008$ and $\mathrm{P}<0.001$, respectively; Fig. $4 \mathrm{C}$ and $\mathrm{D})$, cell cycling (G1 phase: $\mathrm{P}=0.033$ and $\mathrm{P}=0.027$, respectively; $\mathrm{S}$ phase: $\mathrm{P}=0.041$ and $\mathrm{P}=0.003$, respectively; Fig. 4E-G) and cell proliferation (Day 4: $\mathrm{P}=0.007$ and $\mathrm{P}=0.009$, respectively; Fig. $4 \mathrm{H}$ and I). Collectively, these findings indicated that miR-195 serves a tumor suppressive role by downregulating PRR11 expression.

Knockdown of PRRI1 suppresses tumor growth and angiogenesis in vivo. The in vitro assays indicated that PRR11 downregulation inhibited the proliferative and angiogenic activities of tumor cells. To evaluate the biological functions of PRR11 in vivo, we stably suppressed PRR11 expression in DU145 and LNCaP cells through transfection with a lentivirus expression plasmid containing siRNA against PRR11. As shown in Fig. 5A and B, we chose the DU145 and LNCaP cells transfected with the third shRNA for subsequent experiments. The PRR11-suppressed cell lines (PRR11-shRNA) and control PCa cell lines (scramble) were subcutaneously injected into the right side of male nude mice ( 8 mice per group). Compared with the controls, the PCa cells with suppressed PRR11 expression formed significantly smaller tumor nodules (Fig. 5C and D). Additionally, the knockdown of PRR11 markedly reduced the growth of tumor nodules and the weight of tumors in the PRR11-shRNA groups on day 42 when compared with the scramble control groups (Fig. 5E-H). The proliferative and angiogenic abilities of the tumor xenografts were subsequently evaluated via histopathological staining for the proliferative marker Ki67 and pan-endothelial marker CD31. The results showed that in the tumor xenografts of each cell 

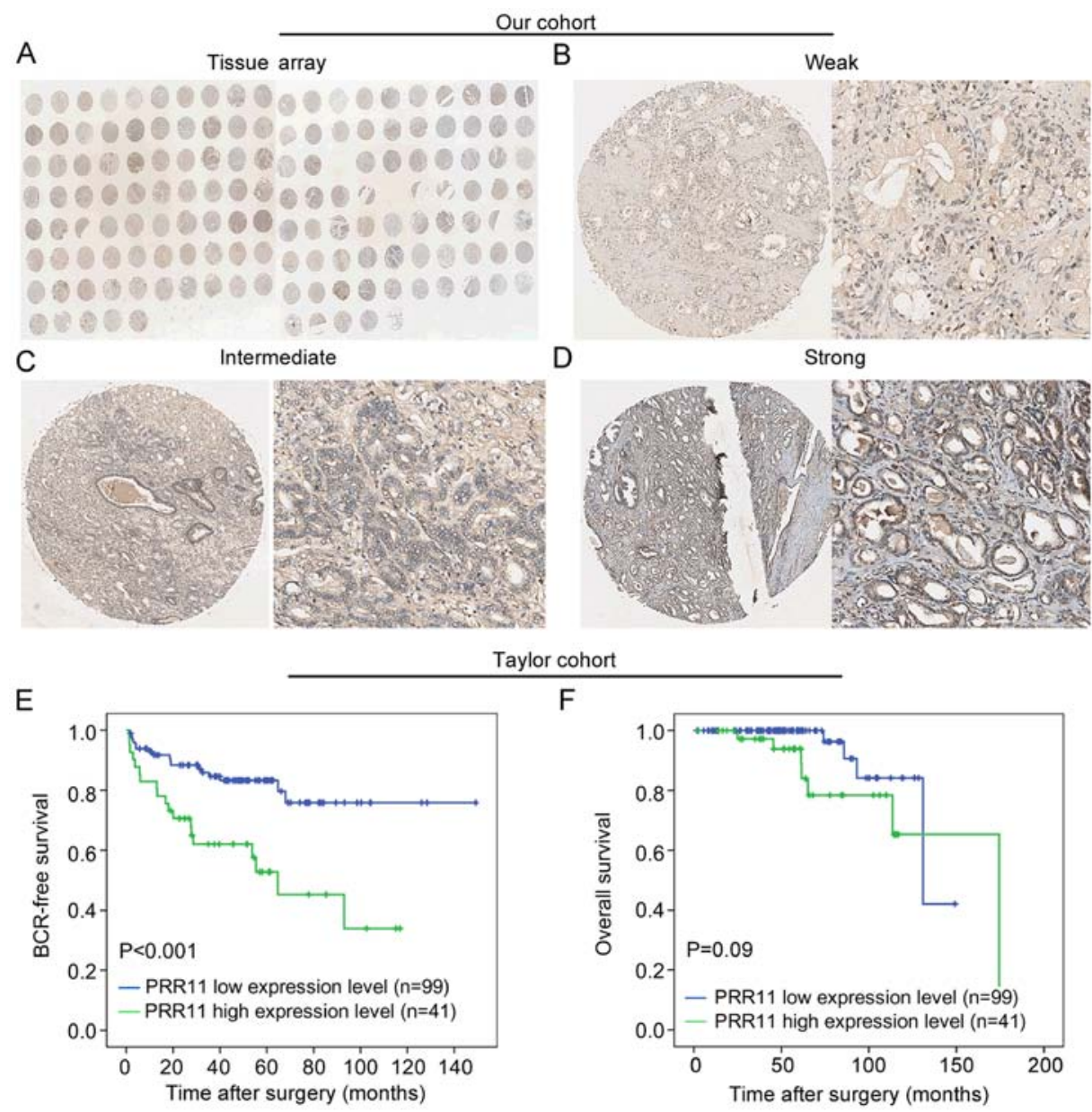

Figure 6. Upregulation of PRR11 expression occurs in aggressive tumors and is associated with poor clinical outcome. (A) A full view of the immunohistochemistry staining for PRR11 in our TMA cohort. (B-D) The immunohistochemistry staining indicated that PRR11 was mainly expressed in the cytoplasm and cellular membrane of PCa and benign glandular epithelium cells. The intensities of the PRR11 immunostaining were weak (B), intermediate (C) and strong (D) (left panel: magnification x40; right panel: magnification x200). (E and F) In the Taylor cohort, PRR11 expression served a prognostic role regarding BCR-free survival but not overall survival, as indicated by Kaplan-Meier analysis. PRR11 overexpression was frequently observed in patients with shorter BCR-free survival time.

line, downregulation of PRR11 reduced the number of vessels $(\mathrm{P}=0.003$ and $\mathrm{P}=0.015$, respectively; Fig. 5I) and suppressed cell proliferation $(\mathrm{P}=0.003$ and $\mathrm{P}=0.038$, respectively; Fig. $5 \mathrm{~J})$.

PRR11 upregulation occurs in aggressive tumors and is associated with poor clinical outcome. To investigate the expression pattern of PRR11 in PCa, immunohistochemical staining for PRR11 was employed to detect the expression pattern and subcellular localization of PRR11 protein in 126 primary $\mathrm{PCa}$ tissues and 22 adjacent non-cancerous prostate tissues (Fig. 6A). As shown in Fig. 6B-D, we identified PRR11-positive staining in the cytoplasm and cellular membrane of PCa and benign glandular epithelium cells, with evenly distributed staining patterns observed at weak, intermediate and strong intensities. PRR11 was recorded as low if the final IRS was no $>4$. As shown in Table III, we found that high PRR11 expression frequently occurred in the PCa tissues $(\mathrm{P}<0.001)$ and in patients with advanced pathological stage $\mathrm{PCa}(\mathrm{P}=0.008)$.

Finally, we validated the clinical value of PRR11 in the Taylor cohort. As shown in Table III, PRR11 was significantly upregulated in PCa tissues relative to non-cancerous tissues
$(\mathrm{P}<0.001)$. More notably, PRR11 overexpression was significantly associated with higher Gleason score $(\mathrm{P}=0.013)$, more advanced pathological stage $(\mathrm{P}=0.012)$, positive metastasis $(\mathrm{P}<0.001)$, positive $\mathrm{BCR}(\mathrm{P}=0.003)$ and shorter overall survival time $(\mathrm{P}=0.007)$ in the $\mathrm{PCa}$ patients (Table III). Kaplan-Meier analysis was also conducted to assess the prognostic value of PRR11 expression in human PCa. The data demonstrated that PRR11 expression level could markedly stratify the patients into high risk and low risk groups regarding BCR $(\mathrm{P}<0.001$; Fig. 6E). However, there was no difference between the overall survival times of patients with high and low PRR11 expression ( $\mathrm{P}=0.09$; Fig. 6F). Meanwhile, univariate analysis revealed that $\mathrm{PRR} 11$ expression $(\mathrm{P}=0.001)$, pathological tumor stage $(\mathrm{P}<0.001)$ and Gleason score $(\mathrm{P}<0.001)$ were significant prognostic factors for BCR-free survival time in patients with PCa (Table IV). Additionally, Cox proportional hazards multivariate analysis also indicated that PRR11 expression level $(\mathrm{P}=0.018)$, pathological tumor stage $(\mathrm{P}=0.003)$ and Gleason score $(\mathrm{P}<0.001)$ were independent predictors of $\mathrm{BCR}$-free survival time in PCa patients (Table IV). Taken together, these findings demonstrated that PRR11 overexpression is associated with aggressive tumor behavior and poor prognosis. 
Table III. Association of PRR11 expression and the clinicopathological characteristics of the PCa in two cohorts.

\begin{tabular}{|c|c|c|c|c|c|c|}
\hline & \multicolumn{3}{|c|}{ Taylor cohort } & \multicolumn{3}{|c|}{ Our cohort } \\
\hline & $\mathrm{N}$ & Mean \pm SD & P-value & Low & High & P-value \\
\hline \multicolumn{7}{|l|}{ Age (years) } \\
\hline$<70$ & 144 & $5.25 \pm 0.36$ & 0.330 & & & \\
\hline$\geq 70$ & 6 & $5.62 \pm 0.83$ & & & & \\
\hline \multicolumn{7}{|c|}{ Preoperative PSA (ng/ml) } \\
\hline$<4$ & 25 & $5.27 \pm 0.44$ & 0.674 & & & \\
\hline$\geq 4$ & 122 & $5.24 \pm 0.32$ & & & & \\
\hline \multicolumn{7}{|c|}{ Gleason score } \\
\hline$<8$ & 117 & $5.18 \pm 0.27$ & 0.013 & & & \\
\hline$\geq 8$ & 22 & $5.50 \pm 0.54$ & & & & \\
\hline \multicolumn{7}{|c|}{ Clinical stage } \\
\hline$<\mathrm{T} 2 \mathrm{~A}$ & 80 & $5.21 \pm 0.31$ & 0.182 & & & \\
\hline$\geq \mathrm{T} 2 \mathrm{~A}$ & 65 & $5.28 \pm 0.39$ & & & & \\
\hline \multicolumn{7}{|c|}{ Pathological stage } \\
\hline $\mathrm{T} 2 \mathrm{~A}-\mathrm{T} 2 \mathrm{C}$ & 86 & $5.17 \pm 0.25$ & 0.012 & 26 & 34 & 0.008 \\
\hline T3A-T4 & 55 & $5.33 \pm 0.42$ & & 14 & 52 & \\
\hline \multicolumn{7}{|l|}{ Metastasis } \\
\hline Negative & 122 & $5.17 \pm 0.23$ & $<0.001$ & & & \\
\hline Positive & 28 & $5.70 \pm 0.60$ & & & & \\
\hline \multicolumn{7}{|c|}{ Biochemical recurrence } \\
\hline Negative & 104 & $5.16 \pm 0.23$ & 0.003 & & & \\
\hline Positive & 36 & $5.42 \pm 0.48$ & & & & \\
\hline \multicolumn{7}{|c|}{ Overall survival } \\
\hline Alive & 131 & $5.21 \pm 0.31$ & 0.007 & & & \\
\hline Died & 19 & $5.66 \pm 0.63$ & & & & \\
\hline \multicolumn{7}{|l|}{ Tissue type } \\
\hline Cancer & 150 & $5.27 \pm 0.39$ & $<0.001$ & 41 & 85 & $<0.001$ \\
\hline Benign & 29 & $5.09 \pm 0.14$ & & 18 & 4 & \\
\hline
\end{tabular}

PSA, prostate-specific antigen.

Table IV. Prognostic value of PRR11 expression for the biochemical recurrence-free survival in univariate and multivariate analyses by cox regression.

\begin{tabular}{|c|c|c|c|c|}
\hline & \multicolumn{2}{|c|}{ Univariate analysis } & \multicolumn{2}{|c|}{ Multivariate analysis } \\
\hline & $\mathrm{HR}(95 \% \mathrm{CI})$ & P-value & $\mathrm{HR}(95 \% \mathrm{CI})$ & P-value \\
\hline Age (years) & $1.02(0.97-1.07)$ & 0.434 & $0.99(0.94-1.06)$ & 0.882 \\
\hline Clinical tumor stage & $1.03(0.53-2.01)$ & 0.926 & $0.73(0.35-1.52)$ & 0.405 \\
\hline Pathological tumor stage & $5.23(2.56-10.68)$ & $<0.001$ & $3.34(1.52-7.33)$ & 0.003 \\
\hline Preoperative PSA & $1.34(0.52-3.46)$ & 0.545 & $1.29(0.47-3.56)$ & 0.625 \\
\hline Gleason score & $11.59(5.84-23.01)$ & $<0.001$ & $5.31(2.70-10.48)$ & $<0.001$ \\
\hline PRR11 & $3.09(1.60-5.95)$ & 0.001 & $2.39(1.16-4.92)$ & 0.018 \\
\hline
\end{tabular}




\section{Discussion}

Traditional predicted methods are unable to accurately stratify PCa patients according to actual clinical outcome, which can lead to overtreatment. There is an urgent need to investigate the molecular mechanism and genetic abnormity underlying PCa progression. miRNAs have been extensively studied over the last two decades, and it has been well established that miRNAs serve essential regulatory roles in virtually all cellular processes, and that altered miRNA expression is involved in many human cancers, including PCa (26). In PCa, miRNAs tend to be preferentially downregulated during $\mathrm{PCa}$ progression and metastasis (27). In our previous study, we firstly reported that miR-195 plays an important role in PCa progression and is involved in tumor invasion, migration and apoptosis. In the present study, we continued to investigate the molecular function and identify novel targets of miR-195 in PCa. The results showed that miR-195 upregulation significantly inhibited angiogenesis and proliferation. Moreover, PRR11 was identified as a novel target of miR-195, and miR-195 expression combined with PRR11 expression was associated with aggressive tumor behavior and poor clinical outcome.

miR-195 has been proven to be involved in many tumor cell processes, including angiogenesis, invasion, migration, proliferation, apoptosis and epithelial mesenchymal transition (EMT) (15-20). Additionally, each individual miRNA can modulate the expression of multiple mRNAs (6), and miRNAs exert their biological functions by regulating target genes. In PCa, miR-195 has been reported to play a regulatory role in the migration, invasion, proliferation, EMT, angiogenesis and metastasis of tumor cells by targeting the 3 ' UTR sequence of RPS6KB1, FGF2, Fra-1 and BCOX1 (21,28-30). In the present study, we reported that miR-195 could suppress the proliferation and cell cycling of PCa cells, and reduce HUVEC tube formation, by downregulating its novel target PRR11.

PRR11, located on chromosome 17q22, has been reported to be closely associated with cell cycle progression $(31,32)$. Multiple highly conserved sequence motifs in the $\mathrm{C}$ terminus of PRR11 protein can be targeted by the anaphase-promoting complex (APC/C) and FBW7-SCF, which may cause PRR11 protein degradation and subsequently cell cycle arrest. This regulatory mechanism is considered to control cell cycle progression (33). Ji et al further found that PRR11 might be involved in cell cycle regulation, especially $S$ phase progression, by altering the expression of cyclin A1, RRM1, MAP4K4, and DHRS2 (32). PRR11 was also demonstrated to participate in various biological processes in tumor cells, including cell invasion, migration and proliferation, by acting as an oncogene $(32,34)$. Moreover, recent studies have shown that PRR11 overexpression is significantly associated with aggressive clinicopathological features and poor clinical outcome in lung cancer, hilar cholangiocarcinoma, gastric cancer and breast cancer $(32,34-36)$. However, the molecular role and clinical relevance of PRR11 in PCa remains unclear. Here, we firstly reported that PRR11 was upregulated in PCa tissues. More importantly, PRR11 overexpression was frequently observed in patients with higher Gleason scores, tumors of more advanced pathological stage and positive metastasis. Additionally, survival analysis revealed that PRR11 could be an independent predictor of the risk of BCR. However, PRR11 expression level was unable to stratify patients according to overall survival time, although this may have been due to the lack of data concerning PCa-specific survival in the Taylor cohort. In vitro assays indicated that the knockdown of PRR11 expression could markedly suppress cell proliferation, the cell cycle and angiogenesis in PCa cells. Meanwhile, the subcutaneous xenograft model further showed that the knockdown of PRR11 significantly suppressed tumor growth and angiogenesis in vivo. These findings demonstrated that PRR11 functions as a promotive factor in PCa progression. Furthermore, critical pathways and differentially expressed genes affected by PRR11 knockdown in PCa were analyzed by microarray analysis employing bioinformatics software. Multiple dysregulated genes were enriched in tumor invasion and metastasis-related pathways, such as CCNA1, RRM1, MAP4K4 and CCL2, which indicated that PRR11 might exert its oncogene role via these important downstream genes (32). However, the definitive mechanism underlying the effects of PRR11 on PCa progression requires further investigation.

In conclusion, our research indicated the role of PRR11 in PCa and identified PRR11 as a new target of miR-195. Notably, PRR11 is an important downstream mediator of the suppressive effects of miR-195 on PCa progression. In addition, miR-195 expression combined with PRR11 expression could accurately stratify PCa patients into different groups according to clinical outcome, and thus the use of these markers may aid to achieve more effective management of $\mathrm{PCa}$ in future clinical practice.

\section{Acknowledgements}

This study was supported by grants from China Postdoctoral ScienceFoundation(2015M580710),Natural ScienceFoundation of Guangdong Province (2016A030310276), National Key Basic Research Program of China (2015CB553706), National Natural Science Foundation of China (81602541, 81370804, 81272813, 81571427, 81402430, 81602541, 81641102), Hospital Young Program Foundation (201523-gyfyy), Special Research Fund for the Doctoral Program of Higher Education (20134423110004), Science and Technology Project in Guangdong (2014A020209085), Colleges and Universities in Guangzhou Yangcheng Scholars Research Project (12A017S), Distinguished Young Talents in Higher Education Foundation of Guangdong Province (2014KQNCX121).

\section{Competing interests}

The authors declare that they have no competing interests.

\section{References}

1. Fraser M, Berlin A, Bristow RG and van der Kwast T: Genomic, pathological, and clinical heterogeneity as drivers of personalized medicine in prostate cancer. Urol Oncol 33: 85-94, 2015.

2. Cooperberg MR, Broering JM, Litwin MS, Lubeck DP, Mehta SS, Henning JM and Carroll PR; CaPSUREInvestigators: The contemporary management of prostate cancer in the United States: Lessons from the cancer of the prostate strategic urologic research endeavor (CapSURE), a national disease registry. J Urol 171: 1393-1401, 2004.

3. Dall'Era MA, Cooperberg MR, Chan JM, Davies BJ, Albertsen PC, Klotz LH, Warlick CA, Holmberg L, Bailey DE Jr, Wallace ME, et al: Active surveillance for early-stage prostate cancer: Review of the current literature. Cancer 112: 1650-1659, 2008. 
4. Capitanio U, Briganti A, Gallina A, Suardi N, Karakiewicz PI, Montorsi F and Scattoni V: Predictive models before and after radical prostatectomy. Prostate 70: 1371-1378, 2010.

5. Ambros V: The functions of animal microRNAs. Nature 431: 350-355, 2004.

6. Jansson MD and Lund AH: MicroRNA and cancer. Mol Oncol 6: 590-610, 2012

7. Cho WC: MicroRNAs: Potential biomarkers for cancer diagnosis, prognosis and targets for therapy. Int J Biochem Cell Biol 42: $1273-1281,2010$

8. Kim WT and Kim WJ: MicroRNAs in prostate cancer. Prostate Int 1: 3-9, 2013.

9. Volinia S, Calin GA, Liu CG, Ambs S, Cimmino A, Petrocca F, Visone R, Iorio M, Roldo C, Ferracin M, et al: A microRNA expression signature of human solid tumors defines cancer gene targets. Proc Natl Acad Sci USA 103: 2257-2261, 2006.

10. Ambs S, Prueitt RL, Yi M, Hudson RS, Howe TM, Petrocca F, Wallace TA, Liu CG, Volinia S, Calin GA, et al: Genomic profiling of microRNA and messenger RNA reveals deregulated microRNA expression in prostate cancer. Cancer Res 68: 6162-6170, 2008

11. Porkka KP, Pfeiffer MJ, Waltering KK, Vessella RL, Tammela TL and Visakorpi T: MicroRNA expression profiling in prostate cancer. Cancer Res 67: 6130-6135, 2007.

12. Ozen M, Creighton CJ, Ozdemir M and Ittmann M: Widespread deregulation of microRNA expression in human prostate cancer. Oncogene 27: 1788-1793, 2008.

13. Fabris L, Ceder Y, Chinnaiyan AM, Jenster GW, Sorensen KD, Tomlins S, Visakorpi T and Calin GA: The potential of MicroRNAs as prostate cancer biomarkers. Eur Urol 70: 312-322, 2016.

14. Xu T, Zhu Y, Xiong Y, Ge YY, Yun JP and Zhuang SM: MicroRNA-195 suppresses tumorigenicity and regulates $\mathrm{G}_{1} / \mathrm{S}$ transition of human hepatocellular carcinoma cells. Hepatology 50: 113-121, 2009.

15. Bhattacharya A, Schmitz U, Wolkenhauer O, Schönherr M, Raatz Y and Kunz M: Regulation of cell cycle checkpoint kinase WEE1 by miR-195 in malignant melanoma. Oncogene 32: 3175 3183,2013

16. Li D, Zhao Y, Liu C, Chen X, Qi Y, Jiang Y, Zou C, Zhang X, Liu S, Wang X, et al: Analysis of MiR-195 and MiR-497 expression, regulation and role in breast cancer. Clin Cancer Res 17: 1722-1730, 2011.

17. Ding J, Huang S, Wang Y, Tian Q, Zha R, Shi H, Wang Q, Ge C, Chen T, Zhao Y, et al: Genome-wide screening reveals that miR-195 targets the TNF- $\alpha / \mathrm{NF}-\kappa \mathrm{B}$ pathway by down-regulating $\mathrm{I} \kappa \mathrm{B}$ kinase alpha and TAB3 in hepatocellular carcinoma. Hepatology 58: 654-666, 2013.

18. Soon PS, Tacon LJ, Gill AJ, Bambach CP, Sywak MS Campbell PR, Yeh MW, Wong SG, Clifton-Bligh RJ, Robinson BG and Sidhu SB: miR-195 and miR-483-5p identified as predictors of poor prognosis in adrenocortical cancer. Clin Cancer Res 15: 7684-7692, 2009.

19. Jia LF, Wei SB, Gong K, Gan YH and Yu GY: Prognostic implications of micoRNA miR-195 expression in human tongue squamous cell carcinoma. PLoS One 8: e56634, 2013.

20. Fu MG, Li S, Yu TT, Qian LJ, Cao RS, Zhu H, Xiao B, Jiao CH, Tang NN, Ma JJ, et al: Differential expression of miR-195 in esophageal squamous cell carcinoma and miR-195 expression inhibits tumor cell proliferation and invasion by targeting of Cdc42. FEBS Lett 587: 3471-3479, 2013.
21. Cai C, Chen QB, Han ZD, Zhang YQ, He HC, Chen JH, Chen YR, Yang SB, Wu YD, Zeng YR, et al: miR-195 inhibits tumor progression by targeting RPS6KB1 in human prostate cancer. Clin Cancer Res 21: 4922-4934, 2015.

22. Taylor BS, Schultz N, Hieronymus H, Gopalan A, Xiao Y, Carver BS, Arora VK, Kaushik P, Cerami E, Reva B, et al: Integrative genomic profiling of human prostate cancer. Cancer Cell 18: 11-22, 2010

23. Maragkakis M, Alexiou P, Papadopoulos GL, Reczko M, Dalamagas T, Giannopoulos G, Goumas G, Koukis E, Kourtis K, Simossis VA, et al: Accurate microRNA target prediction correlates with protein repression levels. BMC Bioinformatics 10: 295, 2009.

24. Lin ZY, Huang YQ, Zhang YQ, Han ZD, He HC, Ling XH, Fu X, Dai QS, Cai C, Chen JH, et al: MicroRNA-224 inhibits progression of human prostate cancer by downregulating TRIB1. Int J Cancer 135: 541-550, 2014.

25. Ong SE, Blagoev B, Kratchmarova I, Kristensen DB, Steen H, Pandey A and Mann M: Stable isotope labeling by amino acids in cell culture, SILAC, as a simple and accurate approach to expression proteomics. Mol Cell Proteomics 1: 376-386, 2002.

26. Iorio MV and Croce CM: microRNA involvement in human cancer. Carcinogenesis 33: 1126-1133, 2012.

27. Bolton EM, Tuzova AV, Walsh AL, Lynch T and Perry AS: Noncoding RNAs in prostate cancer: The long and the short of it. Clin Cancer Res 20: 35-43, 2014

28. Liu C, Guan H, Wang Y, Chen M, Xu B, Zhang L, Lu K, Tao T, Zhang X and Huang Y: miR-195 inhibits EMT by targeting FGF2 in prostate cancer cells. PLoS One 10: e0144073, 2015.

29. Wu J, Ji A, Wang X, Zhu Y, Yu Y, Lin Y, Liu Y, Li S, Liang Z, $\mathrm{Xu}$ X, et al: MicroRNA-195-5p, a new regulator of Fra-1, suppresses the migration and invasion of prostate cancer cells. J Transl Med 13: 289, 2015

30. Guo J, Wang M and Liu X: MicroRNA-195 suppresses tumor cell proliferation and metastasis by directly targeting BCOX1 in prostate carcinoma. J Exp Clin Cancer Res 34: 91, 2015.

31. Zhang C, Zhang Y, Li Y, Zhu H, Wang Y, Cai W, Zhu J, Ozaki T and $\mathrm{Bu}$ Y: PRR11 regulates late-S to $\mathrm{G} 2 / \mathrm{M}$ phase progression and induces premature chromatin condensation (PCC). Biochem Biophys Res Commun 458: 501-508, 2015.

32. Ji Y, Xie M, Lan H, Zhang Y, Long Y, Weng H, Li D, Cai W, Zhu H, Niu Y, et al: PRR11 is a novel gene implicated in cell cycle progression and lung cancer. Int J Biochem Cell Biol 45: 645-656, 2013.

33. Larance M, Ahmad Y, Kirkwood KJ, Ly T and Lamond AI: Global subcellular characterization of protein degradation using quantitative proteomics. Mol Cell Proteomics 12: 638-650, 2013.

34. Chen Y, Cha Z, Fang W, Qian B, Yu W, Li W, Yu G and Gao Y: The prognostic potential and oncogenic effects of PRR11 expression in hilar cholangiocarcinoma. Oncotarget 6: 20419-20433, 2015.

35. Song Z, Liu W, Xiao Y, Zhang M, Luo Y, Yuan W, Xu Y, Yu G and $\mathrm{Hu}$ Y: PRR11 is a prognostic marker and potential oncogene in patients with gastric cancer. PLoS One 10: e0128943, 2015.

36. Zhou F, Liu H, Zhang X, Shen Y, Zheng D, Zhang A, Lai Y and Li H: Proline-rich protein 11 regulates epithelial-to-mesenchymal transition to promote breast cancer cell invasion. Int J Clin Exp Pathol 7: 8692-8699, 2014.

(i) $\ominus$ This work is licensed under a Creative Commons Attribution-NonCommercial-NoDerivatives 4.0 International (CC BY-NC-ND 4.0) License. 